\title{
DETERMINATION OF VANCOMYCIN CONTENT IN DRIED BLOOD SPOTS FOR THERAPEUTIC DRUG MONITORING
}

\author{
MUTASIM AL-GHAZAWI ${ }^{1}$, NOUR EL-HUDA DAOUD ${ }^{2 *}$, KAMAL A. HADIDI ${ }^{3}$, \\ MUHAMMED ALZWEIRI ${ }^{4}$ and SALAHDEIN ABURUZ ${ }^{1,5}$
}

${ }^{1}$ Department of Biopharmaceutics and Clinical Pharmacy, Faculty Of Pharmacy, The University of Jordan, Amman 11942, Jordan

${ }^{2}$ Department of Pharmaceutical Chemistry, Faculty of Pharmaceutical Sciences, The Hashemite University, Zarqa 13133, Jordan

${ }^{3}$ National Drug and Poison Information Center, Division of Forensic Medicine and Toxicology, Jordan University Hospital, Faculty of Medicine, The University of Jordan, Amman 11942, Jordan

${ }^{4}$ Department of Pharmaceutical Sciences, Faculty of Pharmacy, The University of Jordan, Amman, 11942, Jordan

${ }^{5}$ Department of Pharmacology and Therapeutics, College of Medicine and Health Sciences, United Arab Emirates University, Al Ain 17666, United Arab Emirates

\begin{abstract}
Blood spot collection is a simple method to obtain specimens for therapeutic monitoring of drugs, assessing drug adherence, and preventing any potential drug toxicity. A simple chromatographic method for the determination of vancomycin in dried blood spots (DBS) has been developed and validated. Intra and inter-day precisions (measured by $\mathrm{CV} \%$ ) were less than $11.5 \%$ and the accuracy deviation was less than $11 \%$. The limits of detection (LOD) and quantification (LOQ) were 1 and $10 \mathrm{ng} / \mathrm{mL}$, respectively. Interestingly, LOQ is smaller than the smallest vancomycin monitoring level. Stability analysis shows that vancomycin is stable for at least three weeks when stored at 4 to $8^{\circ} \mathrm{C}$. The high sensitivity of detection and short time of analysis (less than $8 \mathrm{~min}$ ), combining with the simplicity of the procedure made the method applicable for monitoring vancomycin in dried blood spots, which might be implemented in routine clinical settings.
\end{abstract}

Keywords: determination of vancomycin, blood spot, therapeutic drug monitoring and chromatography

Vancomycin is an amphoteric glycopeptide antibiotic that has a broad application in the treatment of serious, life-threatening gram-positive infections where resistance and/or allergy has banned the use of other antibiotics. It has a strong bactericidal activity through inhibition of cell wall synthesis in grampositive bacteria (1). It is absorbed minimally from the gastrointestinal tract due to its large hydrophilic structure (2). In the first $24 \mathrm{~h}$ after intravenous administration, about $90 \%$ of vancomycin excrete unchanged by kidneys. The mean half-life in patients with normal renal function is about $6 \mathrm{~h}$. Approximately, 55\% of vancomycin is bound to plasma proteins. It is worthwhile to mention that therapeutic serum levels vary depending on the microorganism involved and the patient's tolerance to the drug $(3,4)$.

The major adverse effect of vancomycin is ototoxicity which has been reported when blood levels exceed $80 \mu \mathrm{g} / \mathrm{mL}$ range (5). Moreover, vancomycin dose adjustment for kidney ill patients (i.e. renal insufficiency and hemodynamic instability) is quite complicated. Thus, the monitoring of the drug levels in the blood is a necessity to reduce the frequency of serious toxic events (6).

Currently, the quantitative measurement method for vancomycin in human blood is an in vitro chemiluminescent microparticle immunoassay (CMIA). It requires relatively large volumes of blood, extensive sample preparation, and combining the sample with expensive reagents. Reagents used to create a reaction mixture utilize expensive kits. The latter requires a long assay time (ca $45 \mathrm{~min}$ ). Moreover, CMIA has a limited range of detection 3-100 $\mu \mathrm{g} /$ $\mathrm{mL}$ and a high potential of interference in presence of a wide range of drugs and/or proteins $(7,8)$. Accordingly, CMIA is less practical for therapeutic

\footnotetext{
* Corresponding author: e-mail: noordaoud@hu.edu.jo,nor8150592@fgs.ju.edu.jo
} 


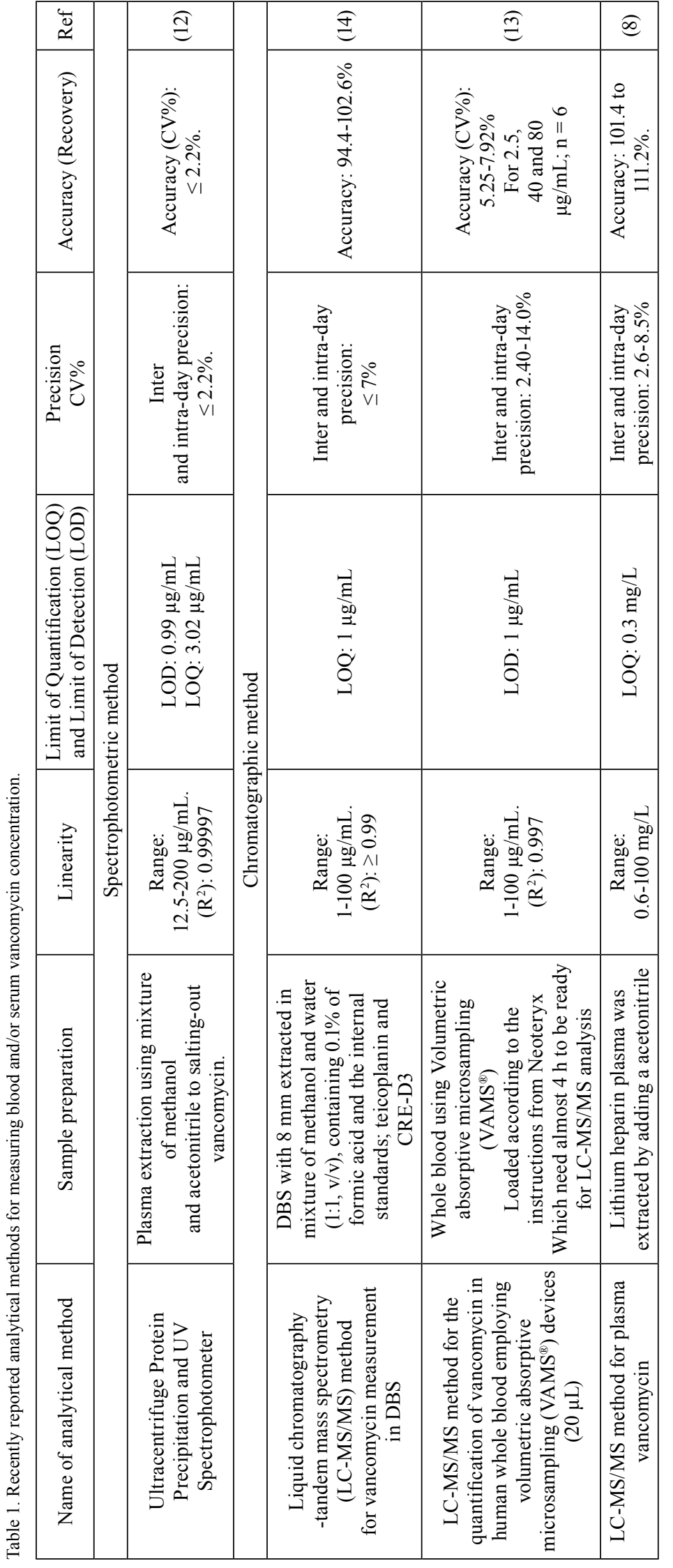

monitoring. Additionally, several liquid chromatographic methods are described in the literature; none of them is suitable for tiny volumes of blood such as those taken from dried blood spots (8-10).

Chemiluminescence, enzyme immunoassay (EIA), kinetic interaction of microparticles in solution (KIMS), enzyme-multiplied immunoassay technique (EMIT), and fluorescence polarization immunoassay (FPIA). are other commercial vancomycin tests used for therapeutic drug monitoring (TDM) (11). However, these tests and others have been recently assessed by Chen et al. (11), where they found significant differences in terms of precision between KIMS and other methods, and accuracy between EMIT, FPIA, and other techniques. Accordingly, laboratories are more likely to underestimate vancomycin concentrations. Thus, transferring vancomycin results between laboratories needs to be done with caution. Examples of other analytical methods: spectrophotometricbased methods (12) and chromatographic-based methods $(8,13,14)$ were compiled in Table 1.

DBS for therapeutic drug assay can facilitate clinical studies and TDM $(9,15-17)$. It is a convenient and inexpensive alternative for whole blood sampling and storage $(18,19)$. It is simple and minimally invasive in particular for children and pregnant women as well as for small animals used in experimental research such as rats and mice. It provides a dried matrix that enhances stability for drug and metabolite (19).

However, using the DBS technique for TDM still need clinical validation, that's capillary blood from finger pricks may have different concentrations from venous blood (20). Moreover, the prediction of plasma or serum 
levels from DBS measurements is affected by the distribution of the drug within the blood cells (21). In addition, obtaining of blood spot sample (5 to $50 \mu \mathrm{L})$ needs very sensitive analytical methods able to measure minimum concentrations, usually below $1 \mu \mathrm{g} / \mathrm{mL}(20,21)$. Currently, there is only one report vancomycin assay based on the DBS technique by Scribel et al. (14). However, they were unable to predict plasma concentrations from DBS accurately in the clinical samples, additionally, their method is limited to vancomycin concentration above $1 \mu \mathrm{g} /$ $\mathrm{mL}$. Therefore, the aim of this study is to develop and validate a chromatographic method able to determine plasma vancomycin concentration by using DBS and sensitive for concentrations below $1 \mu \mathrm{g} / \mathrm{mL}$.

\section{MATERIAL AND METHOD}

\section{Material and chemicals}

Vancomycin hydrochloride (Fisher Scientific ${ }^{\circledR}$, China) was stored at $-20^{\circ} \mathrm{C}$ in a refrigerator until use. Boron trifluoride etherate $\left(\right.$ Merck $^{\circledR}$, Darmstadt), Potassium dihydrogen phosphate monohydrate (Fisher Scientific ${ }^{\circledR}$, India), Sodium hydroxide (Gainland ${ }^{\circledR}$ Chemical Company, UK), Phosphoric acid (Raw Mat., UK), Water HPLC Grade (Labchem ${ }^{\circledR}$, USA), acetonitrile and methanol HPLC Grades (Fisher Scientific ${ }^{\circledR}$, UK) were used without further purification.

Chloroform (Across Organic ${ }^{\circledR}$, USA) and Methanol (AZ ${ }^{\circledR}$ chem for chemicals) were used in the purification of methylated vancomycin.

Trichloroacetic acid (TCA) (Riedel-deHaën ${ }^{\circledR}$ ), perchloric acid (Riedel-deHaën $\left.{ }^{\circledR}\right)$, and dried blood spot collection cards (Whatman, Kent, UK) were used. Blank blood and samples from vancomycintreated patients were donated from Dr. Hadidi's lab.

\section{Instruments}

Shimazdu ${ }^{\circledR}$ HPLC-UV visible detector system (Japan) equipped with LC-20AT pump, SPD-20A detector. Chromatographic data acquired and processed using LC-solution 1.25 software. Microsoft Excel 2010 software for data analysis. The column used was Phenomenex ${ }^{\circledR}$, PhenoSphere - NEXT ${ }^{\mathrm{TM}}$, $5 \mu \mathrm{m}$ particle size $\mathrm{C} 18,120 \AA, 250 \times 4.6 \mathrm{~mm}$. The detector wavelength was set at $260 \mathrm{~nm}$

Rocker ${ }^{\circledR}$ Ultrasonic Bath (Taiwan) was used for mobile phase degassing. Analytical balance $\left(\operatorname{Kern}^{\circledR}\right.$, Germany), pH-meter (Hanna ${ }^{\circledR}$ Company, Romania) coupled with Phelectroid electrode (SenTix ${ }^{\circledR}$ Company, Germany), Simple low-speed Eppendorf centrifuge (Gallenkamp ${ }^{\circledR}$, England) and Rotavapor BUCHI $^{\circledR}$ (Switzerland) were used.

\section{Internal standard (IS) synthesis}

Vancomycin hydrochloride powder $(50 \mathrm{mg})$ was added to $10 \mathrm{~mL}$ of Boron trifluoride-methanol solution $(10 \%)$ at room temperature. The reaction mixture heated at $60^{\circ} \mathrm{C}$ for $30 \mathrm{~min}$, and then cooled to room temperature. For more purification, the TLC separation technique was performed using a mixture of methanol and chloroform in $6: 4$ ratio as a mobile phase, and then the most intense layer was scratched and extracted using $20 \mathrm{~mL}$ of HPLC grade methanol. Then, the solvent evaporated using Rotavapor $\mathrm{BUCHI}^{\circledR}$ at $90^{\circ} \mathrm{C}$ until getting a yellow powder product. The product was methylated vancomycin confirmed by the appearance of $3 \mathrm{H}$ at $3.16 \mathrm{ppm}$ and disappearance of acid peak at $8.9 \mathrm{ppm}$ by using ${ }^{1} \mathrm{H}-\mathrm{NMR}$ spectra, which conducted on a Burker $500 \mathrm{MHz}-$ Avance III spectrometer NMR at The University of Jordan.

\section{Standard preparation}

Two groups of vancomycin standards were prepared: The first group prepared in HPLC-grade water to produce the following concentrations (1.376, $0.688,0.433,0.170,0.130,0.086,0.043,0.0215$, 0.016 , and $0.0086 \mu \mathrm{g} / \mathrm{mL}$ ) and stored at $4^{\circ} \mathrm{C}$ using transparent glass. The second group prepared in phosphate buffer $(65 \mathrm{mM}, \mathrm{pH} 3)$ and stored at $4^{\circ} \mathrm{C}$ using amber glass in refrigerator to ensure highest stability conditions. The following standard concentrations were prepared $(500,400,200,100,90$, $85,50,25,12.5,10,6.2,3.125,2,1.5,0.8,0.6,0.4$, 0.2 , and $0.1 \mu \mathrm{g} / \mathrm{mL}$ ).

\section{QC samples and blood deproteinization:}

Two QC samples were prepared: blood liquid and dried blood spot. In QC blood samples, $100 \mu \mathrm{L}$ of blank blood spiked with $100 \mu \mathrm{L}$ from each vancomycin standard and IS (almost equivalent concentrations). The samples were extracted and deproteinized by $300 \mu \mathrm{L}$ acetonitrile. The precipitate was removed by low-speed centrifugation for $2 \mathrm{~min}$. The other QC samples were prepared by adding $100 \mu \mathrm{L}$ from vancomycin standard and IS to a dried blood spot card. Subsequently, the samples were extracted and deproteinized by $300 \mu \mathrm{L}$ acetonitrile. The precipitate was removed by low-speed centrifugation for $2 \mathrm{~min}$.

\section{Sample preparation and extraction}

Patients' samples were prepared in two forms: blood and dried blood spots with $6 \mathrm{~mm}$ diameter equivalent to $50 \mu \mathrm{L}$ blood volume, which was previously tested using Architect ${ }^{\circledR}$ i1000SR immunoassay analyzer device. Each sample was mixed with $100 \mu \mathrm{L}$ 
from IS then deproteinized using $5 \% \mathrm{v} / \mathrm{v}$ perchloric acid (PCA). All samples were centrifuged before they were injected.

Due to sugar moieties in vancomycin (Figure 1), part of vancomycin is bound with either proteins or hemoglobin in $\operatorname{RBCs}(3,22,23)$. Therefore, there is a demand for an efficient method to extract all vancomycin from the blood. Alzweiri et al. 2012 reported, the efficient methods to precipitate blood proteins: Acids (e.g. 5\% perchloric acid and 10\% trichloroacetic acid) and organic solvents (e.g. acetonitrile). It was found that perchloric acid solution is more efficient than acetonitrile and trichloroacetic acid in extracting vancomycin and salting-out most of the blood sample components. Interestingly, other authors recorded that perchloric acid is immensely able to burst RBCs and precipitate most of the biological sample proteins $(24,25)$.

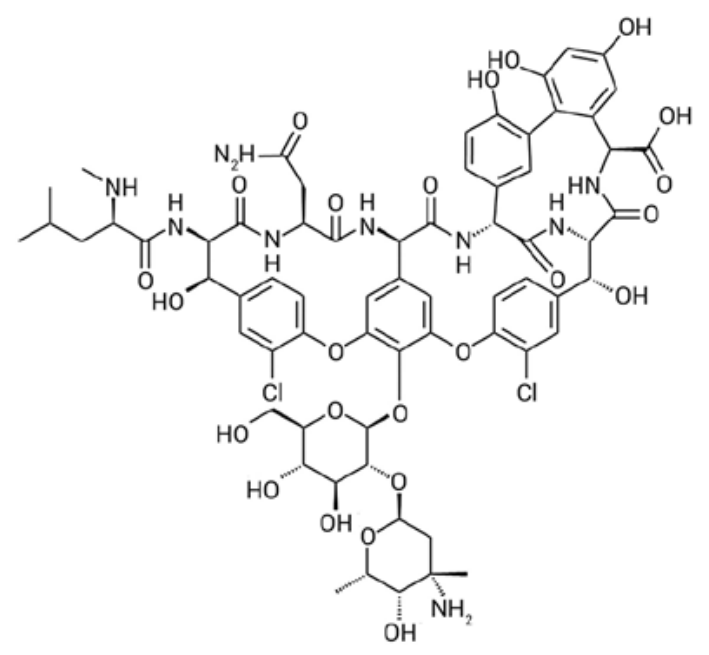

Figure 1. Structure formula of vancomycin.

\section{Chromatography}

HPLC conditions were chosen according to optimized conditions obtained from Serri et al work (26). The mobile phase had an isocratic flow $(1 \mathrm{~mL} / \mathrm{min})$ to keep constant $(85: 10: 5)$ composition ratio between phosphate buffer $(65 \mathrm{mM}, \mathrm{pH} 3)$ to organic modifiers (Acetonitrile and methanol respectively). This ratio was chosen to guarantee solubilization and deionization for the acidic group of vancomycin (analyte) and to achieve a suitable retention time. The mobile phase was filtered through a $0.45 \mu \mathrm{m}$ Millipore filter and degassed ultrasonically before use.

\section{Method validation \\ Standard curves and linearity}

For testing the linearity of the method, seven vancomycin calibration standards were prepared using IS stock solution as a diluent in the range of
$0.1-10 \mu \mathrm{g} / \mathrm{mL}(0.1,0.2,0.4,0.6,0.8,2$, and $10 \mu \mathrm{g} / \mathrm{mL})$. The calibration curve was prepared by plotting the concentrations of the analyte against their peak areas. The slope, the intercept, and determination coefficient $\left(\mathrm{R}^{2}\right)$ were determined. Each reading was the average of three trials.

\section{Limit of quantification and limit of detection}

The sensitivity of the method is evaluated by the limit of detection (LOD) and limit of quantification (LOQ). The LOD is based on a peak height three times greater than the largest baseline fluctuation (signal to noise ratio : $\mathrm{S} / \mathrm{N}$ around 3), and The LOQ was established at a signal to noise ratio $(\mathrm{S} / \mathrm{N})$ of 10 . LOD and LOQ values were experimentally verified by three injections of vancomycin standard solutions.

\section{Precision}

To evaluate the intra- (repeatability), inter-day (reproducibility) precision, four different concentrations were chosen from standard solutions. Precision was expressed as the coefficient of variation (CV\%) for the response (vancomycin peak area), Precision $(\mathrm{CV} \%) \leq 15 \%$ is usually accepted (8).

\section{Accuracy (Recovery)}

The recovery of analytes was calculated by comparing the peak areas (AUC) obtained after extraction of vancomycin from $100 \mu \mathrm{L}$ blood spots spiked with known concentrations of vancomycin and IS and comparing them to those in the standard solution. The following formula was used:

$$
\text { Recovery } \%=\left(\frac{\text { Recovery } \% \text { of analyte }}{\text { Recovery } \% \text { of IS }}\right)
$$

The recovery of vancomycin was determined at six concentrations $(400,200,0.8,0.6,0.4,0.3 \mu \mathrm{g} / \mathrm{mL})$ $(\mathrm{n}=3$ at each concentration

\section{Stability}

The stability test was performed for both blood and dried blood spot (QC) samples for 30 days. Three different vancomycin concentrations for spiked dried blood spot samples were used; 400, 200, and $0.8 \mu \mathrm{g} / \mathrm{mL}(\mathrm{n}=3)$. Additionally, Three different vancomycin concentration for blood spiked samples were used; 400, 0.8 and $0.5 \mu \mathrm{g} / \mathrm{mL}(\mathrm{n}=3)$. All samples were stored at $4-8^{\circ} \mathrm{C}$ for 4 weeks and analyzed at different points in time (1, 2, 7, 21, and 28 days), where each sample thaw at each point then refrozen after injection.

The results were compared with the results of freshly prepared blood samples. Stability was 
considered acceptable if the mean value is within $15 \%$ of the original value at each concentration.

\section{Specificity (selectivity)}

Method specificity was demonstrated through analyzing blank blood spots and patient blood spots who were taking vancomycin. Representative chromatograms are generated to show that other components presented in the sample matrix are resolved from the parent analyte as well as a tiny constant interference with internal standard resolved by subtracting its area from the IS one.

\section{Representativeness of the dried blood spot samples}

To demonstrate that one dried blood spot is representative, two samples type from each patient, blood and dried blood spot samples for each were collected, then prepared and analyzed in duplicate using both the developed method and Architect ${ }^{\circledR}$ i1000SR immunoassay analyzer device for comparison.

\section{RESULTS AND DISCUSSION}

\section{Method development}

Under the applied chromatographic conditions, a group of vancomycin standards, with a wide dynamic range of concentrations, were injected. Several degradation peaks were remarked in standard chromatograms even in low concentrations of vancomycin standard (Figure 2), implying the light sensitivity and/or minimal stability of vancomycin in water.

The stability of vancomycin standards was tested in aqueous solutions with different $\mathrm{pH}$ values. The best stability of vancomycin was obtained in a light-protected container having a phosphate buffer,
pH3 as a solvent. It showed a clean chromatogram with a single peak for low concentration standards; lower than $1 \mu \mathrm{g} / \mathrm{mL}$. However, a new peak for vancomycin dimer was observed at higher concentrations; above $2 \mu \mathrm{g} / \mathrm{mL}$. Interestingly, Schäfer et al. 1996 confirmed that vancomycin exists as an asymmetric dimer resulted from hydrogen bond formation, and this dimer is important to its microbiological activity (22).

Unexpectedly, methylated vancomycin, used as internal standard (IS), eluted earlier than vancomycin (Figure 3); Methylation of vancomycin may reduce intra hydrogen bonding of the molecule rendering it to be more hydrophilic.

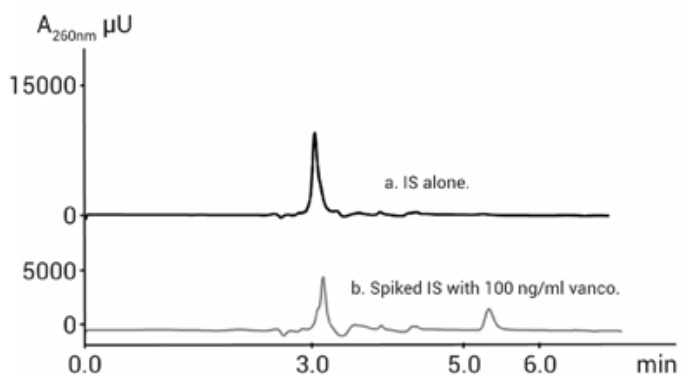

Figure 3. Example of chromatograms generated after injection of IS alone (a) and spiked IS with $100 \mathrm{ng} / \mathrm{mL}$ vancomycin (b).

\section{Method validation \\ Linearity and sensitivity (LOD and LOQ)}

Linearity within the range of $0.1-10 \mu \mathrm{g} / \mathrm{mL}$ was demonstrated by calculating the $\mathrm{R}^{2}$. Each point is established from an average of three determinations. A good linear relationship between detector signal and spiked concentrations was attained, as described by the following linear equation: $\mathrm{Y}=84.157 \mathrm{x}-1.0253\left(\mathrm{R}^{2} 0.9934\right)$, where $\mathrm{Y}$ is the concentration $(\mu \mathrm{g} / \mathrm{mL})$ and $\mathrm{X}$ is the area ratio (AUC drug/AUC IS). The sensitivity of the method was

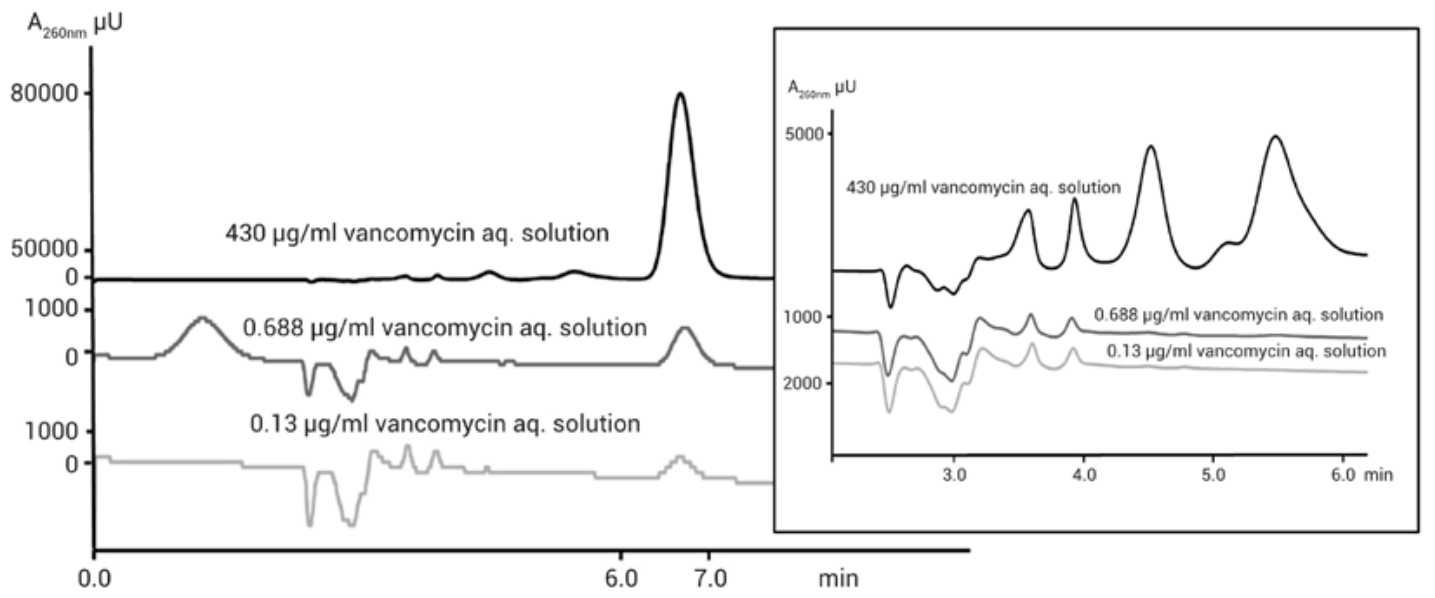

Figure 2. Chromatograms for three concentrations of vancomycin standard in water. Several degradation peaks were noticed indicating instability of vancomycin. 
decided through the measurement of the limit of detection (LOD). The detection limit was determined as the concentration of components giving a signal-to-noise ratio $3: 1$. The LOD was found to be $1 \mathrm{ng} / \mathrm{mL}$ with $\mathrm{CV} \%<3 \%$. The LOQ of vancomycin was determined as the concentrations of $10 \mathrm{ng} /$ $\mathrm{mL}$. Interestingly, LOQ is smaller than the smallest vancomycin monitoring trough level (27-29). Therefore, this method can be used to estimate very little amounts of vancomycin in blood.

\section{Precision and accuracy}

Precision was expressed as the coefficient of variation $(\mathrm{CV} \%)$ for the response (vancomycin peak area), Precision (CV\%) $\leq 15 \%$ is accepted (8). The precision revealed coefficients of variation ranging from $2.69 \%$ to $11.45 \%$ for intra- precision and from $3.06 \%$ to $9.06 \%$ for inter- precision (Table 2).

The accuracy of the method was explored via calculating overall recovery $\%$ (Recovery\% of vancomycin / Recovery\% of IS). The recovery test was performed by comparing the analytical results for the extracted $100 \mu \mathrm{L}$ blood spot samples previously spiked with vancomycin with unextracted standards that represent $100 \%$ recovery. The recovery of vancomycin hydrochloride was demonstrated by comparing the AUC obtained from an amount added to and extracted from blood spot with the AUC obtained for the true concentration of the pure authentic standard. Recovery of vancomycin and IS was found to be consistent, precise, and reproducible with $\mathrm{CV} \%$ $<11 \%$ which is lower than the acceptable limit of $15 \%$ (Table 3) $(8,30)$.

\section{Stability}

The stability of both blood and dried blood spot (QC) samples, previously spiked with vancomycin at different concentration levels was determined by monitoring the AUC responses over a period of 30 days for samples stored at $4-8^{\circ} \mathrm{C}$.

The results showed that retention time and peak area for both vancomycin and IS remained almost unchanged (within acceptable range; ca 15\%). Also, no significant degradation was observed for up to three weeks. However, in the fourth week, the AUC significantly decreased by almost 75 to 50 percentage specifically in the blood samples and spot samples that have $<1 \mu \mathrm{g} / \mathrm{mL}$ vancomycin concentration. (Table 4). In conclusion, the results indicated that the dried blood spot samples could be safely stored at $4-8^{\circ} \mathrm{C}$ for three weeks without observing the degradation of products.

\section{Specificity (selectivity)}

Specificity or selectivity with respect to interferences from endogenous substances in biological fluids was established through analyzing blank blood spots, and blood spots from vancomycin-treated patients (Figure 4). Under assay conditions described above, vancomycin was well resolved with retention times between 6-7 min. The method exhibits selectivity for vancomycin with no interfering peaks was observed in the same chromatographic windows in the blank chromatogram, while a constant minute interference with IS at 3 min retention time has been observed.

Table 2. Inter and intra-day precision.

\begin{tabular}{|c|c|c|c|c|}
\hline & \multicolumn{2}{|c|}{ Intra-day } & \multicolumn{2}{c|}{ Inter-day } \\
\hline Cons $(\mu \mathrm{g} / \mathrm{mL})$ & Mean determined Cons $\pm \mathrm{SD}$ & $\mathrm{CV} \%$ & Mean determined Cons $\pm \mathrm{SD}$ & $\mathrm{CV} \%$ \\
\hline & $\mathrm{n}=3$ & & $\mathrm{n}=3$ & \\
\hline 400 & $395.78 \pm 11.03$ & $2.79 \%$ & $378.96 \pm 23.78$ & $6.04 \%$ \\
\hline 200 & $190.12 \pm 12.54$ & $6.60 \%$ & $198.83 \pm 12.32$ & $5.77 \%$ \\
\hline 10 & $9.39 \pm 1.07$ & $11.45 \%$ & $8.88 \pm 0.72$ & $3.06 \%$ \\
\hline 0.8 & $0.79 \pm 0.02$ & $2.69 \%$ & $0.77 \pm 0.04$ & $9.06 \%$ \\
\hline
\end{tabular}

Table 3. Recovery of vancomycin.

\begin{tabular}{|c|c|c|c|c|c|c|}
\hline $\begin{array}{c}\text { Standard cons } \\
(\mu \mathrm{g} / \mathrm{mL})\end{array}$ & 400 & 200 & 0.8 & 0.6 & 0.4 & 0.3 \\
\hline $\begin{array}{c}\text { Mean } \pm \mathrm{SD} \\
\mathrm{n}=3\end{array}$ & $115.38 \% \pm 9.39$ & $113.15 \% \pm 5.67$ & $106.34 \% \pm 4.23$ & $101.64 \% \pm 4.23$ & $114.68 \% \pm 12.39$ & $118.25 \% \pm 6.67$ \\
\hline $\mathrm{CV} \%$ & $5.64 \%$ & $6.81 \%$ & $3.16 \%$ & $4.16 \%$ & $10.81 \%$ & $5.64 \%$ \\
\hline
\end{tabular}




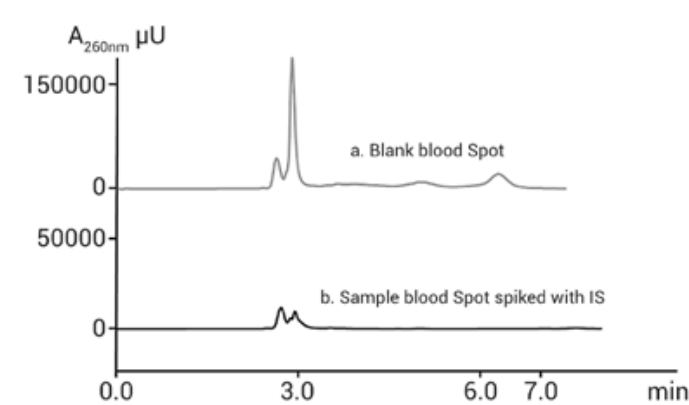

Figure 4. Example chromatogram generated after injection of blank blood spot (a) and sample dried blood spot (b). The method exhibits selectivity for vancomycin with retention time between 6-7 min, and constant tiny interference with IS at $3 \mathrm{~min}$.

\section{Representativeness of the dried blood spot samples}

Coefficients of variation for the three samples that were obtained for each volunteer at different times showed that the coefficient of variation was always less than $0.05 \%$ for direct blood and $<1.5 \%$ for samples of dried blood spots. This clearly indicates that one dried blood spot sample is in fact representing the actual concentration.

\section{CONCLUSION}

Recently, a DBS analysis method is reported (14), the group developed the first DBS analysis method for vancomycin, but their work was limited to vancomycin concentration above $1 \mu \mathrm{g} / \mathrm{mL}$ and the method has a low accuracy to predict clinical data of plasma concentrations from DBS. On other hand, this current work overcomes these limitations by introducing an easily applied method with higher sensitivity (LOD; $1 \mathrm{ng} / \mathrm{mL}$ ) and accuracy.

A chromatographic method for the quantification of vancomycin in the DBS sample was developed and validated. All validation parameters met the acceptance criteria i.e. accuracy, precision and selective, etc. The blood spots proved to be stable for at least 21 days at $4-8^{\circ} \mathrm{C}$.

Small blood volume, short analysis time, combined with the simplicity of the analytical technique make this method useful for monitoring vancomycin concentrations. Our preliminary experience with developing the method indicates that it can be employed in a routine clinical setting.

\section{Acknowledgments}

We wish to thank The University of Jordan represented by the Deanship of Academic Research for supporting and funding the project under financial grant number [1642].

\section{Conflicts of interest}

The authors declare no conflict of interest.

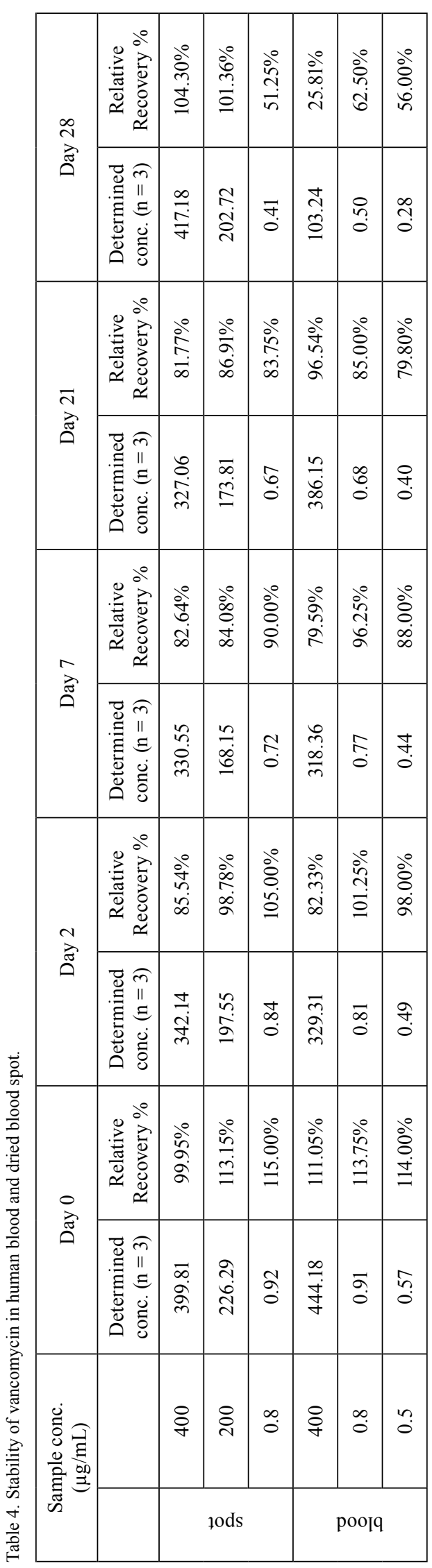




\section{REFERENCES}

1. Rybak M., Lomaestro B., Rotschafer J.C., Moellering R., Craig W., et al.: Am. J. Health Syst. Pharm. 66, 82 (2009).

2. Rao S., Kupfer Y., Pagala M., Chapnick E., Tessler S.: Scand. J. Infect. Dis. 43, 386 (2011).

3. Wilhelm M., Estes L.: Mayo Clin. Proc. 66, 1165 (1991).

4. Moellering Jr R.C., Krogstad D.J., Greenblatt D.J.: Rev. Infect. Dis. 3, S230 (1981).

5. Cantú T.G., Yamanaka-Yuen N.A., Lietman P.S.: Clin. Infect. Dis. 18, 501 (1994).

6. McClain J.B.L., Bongiovanni R., Brown S.: J. Chromatogr. 231, 463 (1982).

7. McConeghy K.W., Liao S., Clark D., Worboys P., Barriere S.L., et al.: Antimicrob. Agents Chemother. 58, 7093 (2014).

8. Oyaert M., Peersman N., Kieffer D., Deiteren K., Smits A., et al.: Clin. Chim. Acta 441, 63 (2015).

9. Abu-Shandi K.H.: Anal. Bioanal. Chem. 395, 527 (2009).

10. Crossley K., Rotschafer J., Chern M., Mead K., Zaske D.: Antimicrob. Agents Chemother. 17, 654 (1980).

11. Chen C.-Y., Li M.-Y., Ma L.-Y., Zhai X.-Y., Luo D.-H., et al.: J. Antimicrob. Chemother. 75, 2110 (2020).

12. Tariq M., Naureen H., Abbas N., Akhlaq M.: J. Anal. Bioanal. Tech. 6, 2 (2015).

13. Moorthy G.S., Downes K.J., Vedar C., Zuppa A.F.: Bioanalysis 12, 1295 (2020).

14. Scribel L., Zavascki A.P., Matos D., Silveira F., Peralta T., et al.: J. Chromatogr. B 1137, 121897 (2020).
15. Al-Ghazawi M., AbuRuz S.: Chromatographia 71, 999 (2010).

16. AbuRuz S., Al-Ghazawi M., Al-Hiari Y.: Chromatographia 71, 1093 (2010).

17. AbuRuz S., Millership J., McElnay J.: J. Chromatogr. B 832, 202 (2006).

18. Knippenberg B., Page-Sharp M., Salman S., Clark B., Dyer J., et al.: Antimicrob. Agents Chemother. 60, 4940 (2016).

19. Timmerman P., White S., Cobb Z., de Vries R., Thomas E., et al.: Bioanalysis 5, 2129 (2013).

20. Antunes M.V., Charão M.F., Linden R.: Clin. Biochem. 49, 1035 (2016).

21. Zakaria R., Allen K.J., Koplin J.J., Roche P., Greaves R.F.: EJIFCC 27, 288 (2016).

22. Schäfer M., Schneider T.R., Sheldrick G.M.: Structure 4, 1509 (1996).

23. Bunn H.F., Gabbay K.H., Gallop P.M.: Science 200, 21 (1978).

24. Peter F., Reynolds R.: Anal. Chem. 48, 2041 (1976).

25. Hogg S., Embery G.: Arch. Oral Biol. 27, 261 (1982).

26. Serri A., Moghimi H.R., Mahboubi A., Zarghi A.: Acta Pol. Pharm. 74, 73 (2017).

27. Zamoner W., Prado I.R.S., Balbi A.L., Ponce D.: Clin. Exp. Pharmacol. Physiol. 46, 292 (2019).

28. Martin J.H., Norris R., Barras M., Roberts J., Morris R., et al.: Clin. Biochem. Rev. 31, 21 (2010).

29. Zasowski E.J., Murray K.P., Trinh T.D., Finch N.A., Pogue J.M., et al.: Antimicrob. Agents Chemother. 62, e01684 (2018).

30. Serri A., Moghimp H., Mahboubi A., Zarghi A.: Acta Pol. Pharm. 74, 73 (2017). 